\title{
Digital transformation of energy sector companies
}

\author{
Victoria Akberdina $^{1 *}$, Ainur Osmonova ${ }^{2}$ \\ ${ }^{1}$ Department of Regional Industrial Policy and Economic Security and Department of Public Sector \\ Economics and Regional Development, Institute of Economics of the Urals Branch of the Russian \\ Academy of Sciences, Moskovskaya st., 29, Yekaterinburg, Russian Federation \\ ${ }^{2}$ Department of Accounting, Analysis and Auditing, Kyrgyz Russian Slavic University, 6 ave. Chui, \\ 720022 Bishkek, Kyrgyzstan
}

\begin{abstract}
Digital transformation is an ongoing process that is driven by the recent advances in digitalization as well as the development of information and communication technologies (ICT) that penetrate all socio-economic fields of everyday life and business. In this paper, we describe the digital transformation of energy companies. We show that successful transformation is based on skills, expertise and knowledge of the employees that need to be created and maintained. In addition, we show that digital competences become a key element in building capacities that are required for the digital transformation. This is of a particular importance for the energy companies that are experiencing major changes on the path of transition toward low-carbon economy and renewable energy.
\end{abstract}

\section{Introduction}

The utility's digital transformation of energy sector would provide all the consumers with access to a more efficient, reliable, and cost-effective energy system. This digital transformation of the energy sector is an ongoing process that involves all countries in the world [1, 2]. Many countries (such as Germany or the United Kingdom) are more successful in this than the others. In summer 2020, United Kingdom managed to generate its electricity without using its coal plants and there are plans to reach about $80 \%$ of carbon-free transport and heating by $2030[3,4]$. In the United States, the plans to shift towards the green and fossil-free economy with zero greenhouse gas emissions are estimated at 2050 [5]. Of course, this process will take a long time, since the major changes that are needed are not in the industry itself but in the minds of the people. Therefore, it is important to assist individuals and companies in finding solutions to accelerate the transformation of the energy sector into a renewable energy dominated sector, while electrifying the use of sectors to achieve deeper decarbonisation [6]. The digital transformation in the renewable energy sector allows it to automate the development of new technologies such as smart grids, energy storage and smart grid systems. There should be solutions for individuals, cities and businesses, with a focus on energy efficiency and security, drawing on the expertise of energy sector experts in its

\footnotetext{
* Corresponding author: akberdina.vv@uiec.ru
} 
member countries. These solutions should allow the business companies to develop personalized services that are tailored to the expectations of customers. Digitalization is driving major changes in the energy sector, driving innovation and influencing business models. Future drivers of the energy markets would create a digital backbone that supports the transition from fossil fuels to renewable energy and creates an energy system that is connected to our personal and local ecosystems $[7,8]$.

In addition to that, recent changes in the energy industry in connection with COVID-19 and the pandemic are leading companies to think about how innovative technologies can affect their future business. The use and application of the latest technologies to existing operations will enable more efficient and efficient use of energy resources in the future which will create pioneers of digital transformation with trusted partners worldwide [9, 10].

Digital technologies are already playing a crucial role in accelerating the decarbonization effort. However, in order for digitalisation to realise its full $\mathrm{CO}_{2}$ potential, rigorous analysis is needed to guide good policy. The energy sector which is driven by advanced technologies, declining costs and the emergence of new markets, is on the cusp of a new digital age, with far-reaching implications for climate change and energy security. The trend towards greater digitisation of energy is made possible by advances in data analysis and networking. This includes the falling costs of sensors, the increasing amount of data from sensors and data storage and the emergence of new markets. Major industries and sectors have increasingly adopted these technologies in recent years, and the energy sector is no exception $[11,12]$.

The energy and utilities sectors are the main participants in the digital transformation of the energy sector. Electricity is generated by transmitting it through transmission and distribution networks and transmitting it to final consumers in the form of generation, transmission, distribution and storage. Digitalisation has accelerated the transition from a multi-directional to a decentralised energy system, in which all sources of demand are actively involved in balancing supply on a scale. Highly connected systems are emerging that blur the distinction between traditional providers and consumers and open up opportunities for both [13]. Digitalization has also transformed sectors such as road transport, where connectivity, automation, and further electrification of mobility could dramatically transform the sector. Automation and data also influence the approach to production, increasing the efficiency of factory environments. Having seen the effectiveness of innovative technologies in other industries, the energy sector nowadays does not hesitate to adapt to emerging technological trends, including the use of smart grids and, in all clarity, technologies such as smart meters [14]. Although they have the potential to transform the energy sector equally drastically, they have yet to penetrate it and make their mark and significantly penetrate it. These technologies are reinventing the way energy and utilities do business, engage, and interact with their customers and the masses. The digital transformation solutions the energy sector needs to be innovative and better equipped for the future are becoming very important. IoT, data analysis and machine learning are becoming the main elements in supporting the digital transformation of the business models and processes of the established energy companies.

\section{Digital technology for producing and distributing energy}

Decentralised energy resources are being used in an increasingly decentralised energy system. Driven by the falling cost of renewable energy sources such as wind, solar and decentralised renewables, fossil-fuel generators have been the main beneficiaries in recent years. These changes present significant challenges to the future of power generation and distribution in the United States, China and the rest of the world [15].

At the same time, new resources and technologies offer opportunities: the cost of electricity infrastructure can be reduced, enabling the energy sector to achieve ambitious 
decarbonisation targets. As utilities integrate information and communication technologies to modernize the power system, there is an opportunity to be reliable and cost-effective - and to effectively increase decentralized generation as an alternative to centralized power plants and the provision of renewable energy [16]. Existing low-cost decentralised power generation methods such as wind and solar can be used to generate electricity through a combination of solar panels, wind turbines and other renewable sources. Decentralised generation also benefits the environment, as its use reduces the amount of electricity that needs to be generated in central power plants. This in turn could reduce the environmental impact of centralised electricity generation, in particular in the case of wind, solar and geothermal generation. Smart Grid technology is an opportunity to modernise energy distribution and ensure that the network can ensure communication between utilities and consumers. Smart grids also offer the potential for decentralised energy, and this can become a reality if every house becomes a miniature power station [17]. Since each house produces its own electricity, the electricity can be diverted from the plants, even from the house itself, if the plants fail. Rooftop solar panels and smart grids go hand in hand, but that will become a reality in the near future, when homes become miniature power plants.

Figure 1 that follows outlines the model of digital transformation that is typically achieved through capability and competence. This is completed using strategic decisions and investments and yields knowledge, skills and expertise that are required for the successful digital transformation of energy companies.

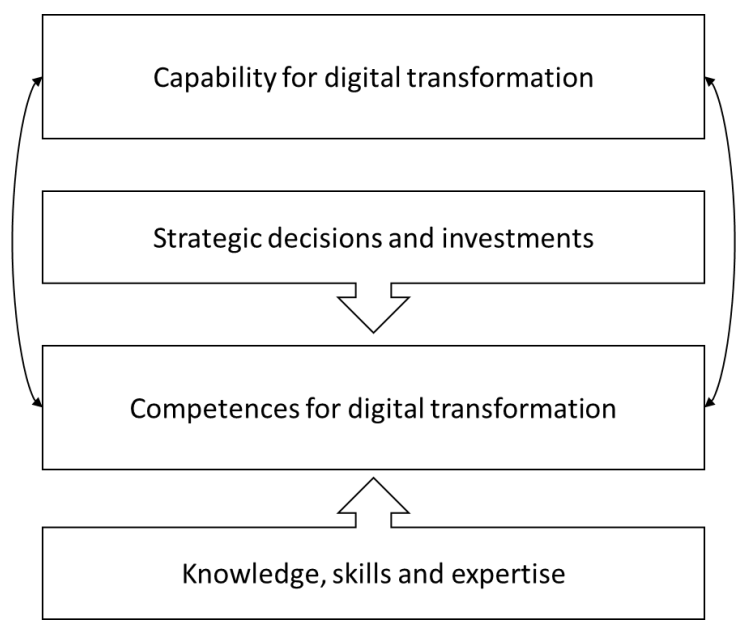

Fig. 1. Digital transformation through capability and competence

The most important of the digital transformation in the energy sector is that we get it right as the electricity grid develops and cities commit to buying electricity from renewable-energy developers. By continuously collecting and synthesizing data from millions of smart sensors, future power grids will depend on coordination through automated smart meters, smart grids and smart energy management systems. Almost $\$ 25$ trillion will be invested in the modernized smart energy infrastructure in the United States and other countries over the next 10 years [18]. It becomes clear that we need to invest in edge analytics and computing as we strive for a smarter, more efficient and more cost-effective energy system. When people first hear about smart grid initiatives, they often connect smart meters to smart grids. But smart meters are a development that began decades ago, leading to the creation of the United States Energy Information Administration (EIA) and the National Renewable Energy Laboratory. Smart grids make electrical systems more reliable and efficient, helping utilities to reduce 
power losses, identify and resolve problems faster. Micro grids can play an important role in building a low-carbon future by bringing resilience to the main grid, optimising energy costs, enabling renewable energy hosting, improving the integration of electric vehicles and improving energy availability. Smart grids can help consumers manage energy consumption in times when demand is significantly higher or when reduced energy requirements are needed to support system reliability. Smart appliances in homes, offices and factories can inform consumers about their energy management systems at a time when appliances are consuming relatively much more expensive electricity [19]. These alarm systems help consumers and their intelligent systems to optimally adapt settings which, if supported, can reduce consumers' energy costs. The topic also includes strategies on electricity and electronic management in the context of the use of renewable energy and the conversion of renewable energy. It is about the use of smart grids, smart energy management systems and smart devices to improve energy efficiency and efficiency. Planning and operation of energy systems related to renewable energies and the use of intelligent energy management systems in the context of electricity generation and distribution systems.

However, investment in smart homes and buildings could provide enough energy to generate more electricity than Italy and Australia combined. Buildings consume the most electricity, and the digitalization could reduce energy consumption by about $10 \%$ by improving operating efficiency in addition to the efficiency gains from LEDs. By using decentralised energy sources such as solar, wind, water, geothermal and biomass, digitalisation can blur the distinction between supply and demand and provide consumers with opportunities to interact directly with demand or supply in real time [20]. This type of embedded demand - lateral flexibility - is also a key element of the vision for the future of renewable energy in the energy sector.

\section{Self-generation of renewable energy}

Solar and wind turbines are a great way to reduce energy costs, increase property values and benefit the environment. In order to promote the self-generation of renewable energy, many energy companies have a tariff for the net energy meter service, which covers the cost of using electricity from solar panels, wind turbines, photovoltaic systems and other renewable energy sources [21]. Solar modules or wind turbines have improved significantly in the last decade, and incentives and financing from the federal, state and local governments have made it easier than ever to install in people's own household systems. These programs enable private and business customers to promote renewable energy without having to make costly investments. Customers generators and plants are designed to operate at a lower cost than conventional fossil fuel generators such as coal, natural gas and nuclear power. All of this allows private and small-business owners to generate electricity from renewable sources to sell the surplus power immediately. Moreover, this provides incentives to promote the development of existing and emerging decentralised energy resources such as solar, wind and geothermal energy. Such programs boost the efforts to promote energy efficiency, increase renewable energy, and deliver cost-effective, reliable, and clean energy to the households and businesses. Incentives for the qualification of decentralised energy systems for electricity meters, which are to be installed on the customer's side, are also poplar [22]. Qualified technologies include solar, wind, geothermal, hydro, biomass, waste heat, biofuel and wind power plants. Generators must use micro-turbines or fuel cells and be powered by renewable energy sources such as wind or solar energy or biomass or biofuel. The generator must be located on the customer's premises behind the meter and must cover part or all of the customer's electricity needs. Customers can support green electricity by contributing a monthly contribution to their electricity bill. This can save them money on their electricity bills and reduce their electricity bills. Self-producing energy means that a user or group of 
users saves energy and generates locally by using renewable energy sources [23]. Then the participants of Green Switch can claim that the electricity comes from renewable sources. The self-production of energy from renewable sources such as sun, wind and water are crucial for a sustainable economy and society. Decarbonisation of the energy sector is feasible, but supply is not nearly sufficient to meet demand. In Europe, an estimated 8 billion EUR has already been allocated to the use of renewable energy in the energy sector. This explains why fossil fuels need to be replaced by renewable energy, according to a report by the International Energy Agency. In 2000, renewables accounted for nearly $9 \%$ of the share, and wind power provided more than half of all the electricity produced in the United State, with 41 states and two territories in operation. Wind energy includes both large wind farms (large turbines that can generate electricity) and small turbines on commercial sites. Looking at the wind map for the United States, one can see where power is generated, and looking at the wind maps for each state and area more information can be obtained [24].

The "do not need" segment has been growing for years as prices for renewable energy fall. Battery-powered energy storage is needed if someone wants to accumulate energy for later use when there is less sunlight. Electronic devices convert the direct current generated by photovoltaic systems into alternating current. Mini - wind energy uses the kinetic energy of the wind as a generator for a small generator. The electricity generated by small wind turbines can be used to meet domestic needs, making it an ideal solution for self-consumption of electricity. Solar panels, also known as photovoltaics (PV) and wind turbines have been used in local renewable energy projects. The cost of solar panels has fallen by almost $70 \%$ in the last decade, contributing to a large number of installations across the country. With the introduction of renewable energy sources, customers now have an option for renewable energy for the first time in their lives [25].

\section{Microgrids and local energy solutions}

Microgrid is a localised network that separates itself from the traditional network, operates autonomously and functions as if the main network had failed. Microgrids can strengthen grid resilience, help alleviate grid disruptions and support a flexible and efficient electricity grid by allowing for the increasing use of decentralised energy resources such as wind, solar, hydro, geothermal, biomass, wind and hydro [26]. A microgrid can be selfsufficient in generating, transmitting, distributing and storing electricity and can operate independently in the event of a major power failure or temporary shutdown of the primary grid. This technology thus gives local energy producers greater independence and helps to keep costs down [27].

Sustainable microgrids could also empower the poor by expanding access to Internet and electricity in rural areas by providing such services without central grids and gasolinepowered generators [28]. Certain developments have also shown that micro-grids can turn renewable energy into a source of electricity for households in some rural areas that generate more than enough electricity, with surplus energy being sold back to the central grid. Microgrid is an on-site energy system that integrates decentralised energy resources for electricity generation. Generally, a microgrid represents a decentralised energy resource load that can be operated, locally controlled or operated independently of the main grid. Microgrids operate independently of the power grid and can be operated for up to 30 days without a central power grid. Microgrids are an on-site energy system with a large number of distributed energy resources and loads, which are operated, landed or locally operated and controlled independently [29]. Microgrids can provide temporary local power generation to avoid peak loads and store excess solar and wind energy, allowing them to send electricity when needed or work around the clock. Together, these price reductions will enable variable clean energy storage to be integrated into the renewable micro-grids that support the main 
electricity grid and can operate independently. Today, sophisticated energy management systems enable project developers to develop microgrids that can incorporate decentralized energy sources such as solar, wind, biomass, heat and power plants, geothermal, hydroelectric and wind turbines. The programme aims to use microgrids to power the mission - critical facilities in the event of a loss of supply or power. Most importantly, they can also keep power plants and other critical infrastructure such as hospitals, schools, hospitals and hospitals running if the main grid fails.

With the infrastructure and resources, microgrids can support many of the operational goals and challenges that distribution networks currently face. Utilities are exploring the potential of new sources of revenue to make microgrids a viable alternative to traditional power generation and distribution systems. Currently, the United States electricity grid is centralized, with a handful of large utilities handling the bulk of electricity generation [30].

While local consumers can be serviced by the utility in the event of a power failure, new, more decentralized systems can also be used to address systemic risks such as large-scale blackouts. A micro grid is a system of generation, energy storage and load that normally operates without connection to a traditional supply network. One can say that a microgrid is a local energy grid with control capabilities, which means it can be disconnected from the traditional grid and operated autonomously. Different from traditional models, microgrids are defined as electricity production at the place of consumption, which is independent of other generators. There can be no need to be disconnected from a traditional power supply network, which is what micro grids need to operate without power in the event of a power failure. The microgrid can be isolated from the conventional grid and continue to supply electricity. In the event of a power failure or other power failure, it can operate autonomously. A precursor to microgrids is a simple system that consists largely of a central power plant that supplies a single building or campus with diesel generators as a backup. There are several semi-autonomous nodes that operate in parallel and each have its own power supply and distribution system. Microgrids may never be abolished, but bringing more power generation, management, and consumption under local control will make everyone less dependent on them.

All of the above offers a new approach to aggregating small, decentralized energy resources that does not include physical switches that can link them to a grid. Virtual aggregations can combine the results and treat them as a single entity participating in the network services market.

\section{Conclusions}

Overall, it becomes clear that successful digital transformation is based on skills, expertise and knowledge that need to be developed through investments and public and private support and guidance. Surely, this represents a long-range process that can be helped by the advancements in digitalization and information and communication technologies in all socio-economic fields of business and society. However, this process has already started and is likely to continue in the face of the commitments to fighting the effects of global warming and climate change that are in turn marked by the decarbonization of the energy sector and the massive deployment of renewable energy sources such as solar batteries or wind turbines.

Thence, one would agree that digital transformation of energy companies is a challenge since these companies are faced with numerous profound changes as they are getting involved into the ongoing transition to the low-carbon economy and (self-generated) renewable energy sources. 


\section{Acknowledgements}

The article was prepared with the support of RFBR grant No. 20-010-00719 "Simulation of cross-industrial networking processes in the industrial complex based on hybrid technologies".

\section{References}

1. E. Abad-Segura, M. González-Zamar, J. Infante-Moro, G. Ruipérez García, Sustainability, 12(5), 2107 (2020)

2. T. Kurbatova, Marketing and management of innovations, 4, 374-383 (2017)

3. H. Cockburn, https://www.independent.co.uk/climate-change/news/coal-free-power-ukrecord-time-2020-how-long-renewable-energy-a9570891.html (2020)

4. D. Newbery, M. Pollitt, R. Ritz, W. Strielkowski, Renewable and Sustainable Energy Reviews, 91, 695-707 (2018)

5. E. Larson, C. Greig, J. Jenkins, E. Mayfield, A. Pascale, C. Zhang, J. Drossman, R. Williams, S. Pacala, R. Socolow, EJ Baik, R. Birdsey, R. Duke, R. Jones, B. Haley, E. Leslie, K. Paustian, A. Swan, Net-Zero America: Potential Pathways, Infrastructure, and Impacts, Princeton University, https://acee.princeton.edu/rapidswitch/projects/netzero-america-project (2020)

6. V. Arabzadeh, J. Mikkola, J. Jasiunas, P. Lund, Journal of Environmental Management, 260, 110090 (2020)

7. K. Hojckova, H. Ahlborg, G. Morrison, B. Sanden, Research Policy, 49(8), 104046 (2020)

8. M. Jayaratne, G. Sullivan Mort, C. D’Souza, Sustainability, 11(24), 7076 (2019)

9. M. Fu, H. Shen, Energy Research Letters, 1(1), 12967 (2020)

10. R. Elavarasan, G. Shafiullah, R. Kannadasan, V. Mudgal, M. Arif, T. Jamal, S. Subramanian, V. Balaguru, K. Reddy, U. Subramaniam, Applied Energy, 279, 115739 (2020)

11. N. Kittner, F. Lill, D. Kammen, Nature Energy, 2(9), 1-6 (2017)

12. S. Tagliapietra, G. Zachmann, O. Edenhofer, J. Glachant, P. Linares, A. Loeschel, Energy Policy, 132, 950-954 (2019)

13. N. Hossein Motlagh, M. Mohammadrezaei, J. Hunt, B. Zakeri, Energies, 13(2), 494 (2020)

14. G. Rausser, W. Strielkowski, D. Streimikiene, Energy \& Environment, 29(1), 131-146 (2018)

15. V. Madonna, P. Giangrande, M. Galea, IEEE Transactions on Transportation Electrification, 4(3), 646-659 (2018)

16. T. Napp, S. Few, A. Sood, D. Bernie, A. Hawkes, A. Gambhir, Applied Energy, 238, 351-367 (2019)

17. G. Dileep, Renewable Energy, 146, 2589-2625 (2020)

18. U.S. Department of Energy, https://www.energy.gov (2020)

19. I. Abubakar, S. Khalid, M. Mustafa, H. Shareef, M. Mustapha, Renewable and Sustainable Energy Reviews, 67, 235-245 (2017)

20. S. Hu, D. Yan, E. Azar, F. Guo, Building and Environment, 175, 106807 (2020)

21. C. Ines, P. Guilherme, M. Esther, G. Swantje, H. Stephen, H. Lars, Energy Policy, 138, 111212 (2020)

22. R. Fakhry, The Electricity Journal, 30(6), 31-41 (2017)

23. A. Papadopoulos, Renewable Energy, 149, 103-114 (2020)

24. L. Bird, M. Bolinger, T. Gagliano, R. Wiser, M. Brown, B. Parsons, Energy Policy, 33(11), 1397-1407 (2005) 
25. D. Gielen, F. Boshell, D. Saygin, M. Bazilian, N. Wagner, R. Gorini, Energy Strategy Reviews, 24, 38-50 (2019)

26. B. Chen, J. Wang, X. Lu, C. Chen, S. Zhao, IEEE Transactions on Smart Grid, 12(1), 18-32 (2020)

27. A. Hirsch, Y. Parag, J. Guerrero, Renewable and sustainable Energy reviews, 90, 402$411(2018)$

28. M. Khodayar, The Electricity Journal, 30(4), 68-74 (2017)

29. S. Rangu, P. Lolla, K. Dhenuvakonda, A. Singh, International Journal of Energy Research, 44(13), 9889-9911 (2020)

30. A. Cheng, B. Tarroja, B. Shaffer, S. Samuelsen, Journal of Power Sources, 401, 175-185 (2018) 